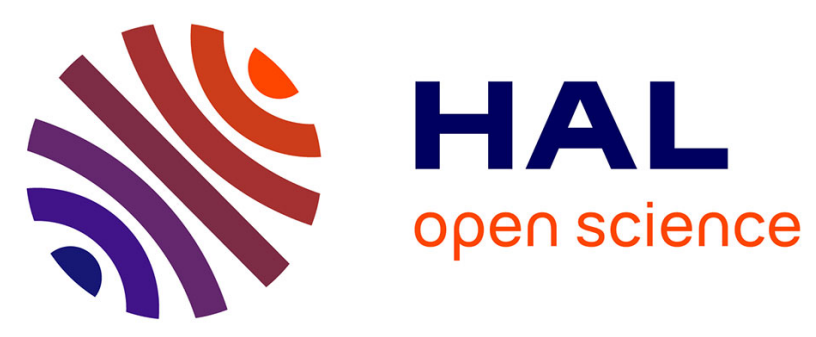

\title{
Wideband Fully Differential Current Driver with Optimized Output Impedance for Bioimpedance Measurements
}

Achraf Lamlih, Philippe Freitas, Stéphane David-Grignot, Jérémie Salles, Vincent Kerzérho, Fabien Soulier, Serge Bernard, Tristan Rouyer, Sylvain Bonhommeau

\section{To cite this version:}

Achraf Lamlih, Philippe Freitas, Stéphane David-Grignot, Jérémie Salles, Vincent Kerzérho, et al.. Wideband Fully Differential Current Driver with Optimized Output Impedance for Bioimpedance Measurements. ISCAS: International Symposium on Circuits and Systems, May 2018, Florence, Italy. 10.1109/ISCAS.2018.8351464 . lirmm-01874027

\section{HAL Id: lirmm-01874027 https://hal-lirmm.ccsd.cnrs.fr/lirmm-01874027}

Submitted on 13 Sep 2018

HAL is a multi-disciplinary open access archive for the deposit and dissemination of scientific research documents, whether they are published or not. The documents may come from teaching and research institutions in France or abroad, or from public or private research centers.
L'archive ouverte pluridisciplinaire HAL, est destinée au dépôt et à la diffusion de documents scientifiques de niveau recherche, publiés ou non, émanant des établissements d'enseignement et de recherche français ou étrangers, des laboratoires publics ou privés. 


\title{
Wideband Fully Differential Current Driver with Optimized Output Impedance for Bioimpedance Measurements
}

\author{
Achraf Lamlih ${ }^{1}{ }^{2}$, Philippe Freitas ${ }^{1}$, Stephane David-Grignot ${ }^{1}$, Jérémie Salles ${ }^{1}$, Vincent Kerzérho ${ }^{1}$, \\ Fabien Soulier $^{1}$, Serge Bernard ${ }^{1}$, Tristan Rouyer ${ }^{2}$ and Sylvain Bonhommeau ${ }^{3}$ \\ ${ }^{1}$ LIRMM, CNRS/University of Montpellier, 161 rue Ada 34095 Montpellier Cedex 5, FRANCE \\ ${ }^{2}$ Ifremer/MARBEC, Av. J. Monnet, 34203 Sète, France \\ ${ }^{3}$ Ifremer/DOI, rue J. Bertho, 97822 Le Port, France \\ contact: firstname.lastname@lirmm.fr / firstname.lastname@ifremer.fr
}

\begin{abstract}
This paper presents a wideband fully differential current driver architecture suitable for bioimpedance measurements. It uses an improved regulated cascode to enhance output impedance, enabling accurate measurements of transfer impedances at low and high frequencies. The current driver architecture maximizes the output voltage swing. An independent reference voltage is used in order to compensate the process variations of the output common mode voltage. The circuit was designed in $0.18 \mu \mathrm{m}$ CMOS AMS process, operating from 1.8V supply voltage. The silicon area is $0.26 \mathrm{~mm}^{2}$. The current driver has a $67 \mathrm{MHz}$ bandwidth and can provide a maximum output current of $600 \mu \mathrm{A}$ peak to peak with a Total Harmonic Distortion (THD) below $0.3 \%$ at low frequencies increasing to $0.6 \%$ at $8 \mathrm{MHz}$. Due to the use of regulated cascodes in the output stage, the circuit achieves a 79M $\Omega$ output impedance at low frequencies decreasing to $324 \mathrm{~K} \Omega$ at $1 \mathrm{MHz}$, with an output voltage swing of $0.95 \mathrm{~V}$.
\end{abstract}

Keywords-Operational Transconductance bioimpedance, current driver, regulated cascode

\section{INTRODUCTION}

Bioimpedance spectroscopy (BIS) is a technique increasingly used for measuring the electrical properties of biological tissues [1]. Since bioimpedance is a function of the physiological processes, variations of the composition of biological tissues can be seen as variations of the electrical impedance of the tissue.

In order to measure bioimpedance, current stimulation is generally used. Thus, a current containing a single or multiple frequencies is injected in the tissue under test via electrodes, the bio-modulated response voltage is then measured to determine the impedance transfer function.

For a rigorous characterization of the biological tissue composition, the complex impedance needs to be analyzed over a large range of frequencies. In fact, each tissue molecule has a different response to a given frequency. Indeed the electrical permittivity of biological tissues decreases in three main steps corresponding to three dispersions [2] : the $\alpha$ dispersion (10 Hz to $10 \mathrm{KHz})$, the $\beta$ dispersion $(10 \mathrm{KHz}$ to $10 \mathrm{MHz})$ and the $\gamma$ dispersion $(\geq 10 \mathrm{MHz})$. Since $\alpha$ and $\beta$ dispersions are associated with the most relevant biological aspects [3], the current should have a constant amplitude over these frequency ranges. This is achieved by having a large output impedance compared to the load. In fact, at lower frequencies, the sum of the electrodes-interface and tissue impedances have the highest magnitudes. Whereas at higher frequencies, stray capacitance represents the biggest challenge since it shunts the output resistance of the current driver which reduces its value.

Due to low voltage supply specifications and the need for high output current amplitudes necessary to ease the response analysis, the output voltage swing is a critical parameter for the current driver. Also, in implanted measurements applications, the electrode-interface impedance may increase due to biological effects such as fibrosis. Thus, care must be taken to ensure a maximal output voltage swing.

The Howland current driver is widely used in bioimpedance applications. However, the output impedance and stability of the Howland source are dependant of the accurate matching of the resistors in the positive and negative feedback [4], which makes it more suitable for discrete designs.

An alternative option is to use Operational Transconductance Amplifier (OTA) based current drivers, which are well suited for applications requiring a fully integrated circuit.

The integrated current driver needs to have a large bandwidth to cover at least the first two frequency dispersions. The output impedance should be maximized especially in low frequencies in order to be insensitive to the variation of the relatively high electrode-tissue interface impedances.

A current driver architecture providing high output impedance has been introduced in [5], an improved version of this topology has been described in [6] . It is capable of providing high output impedance using negative feedback that senses and regulates the output current. However, the design is complex and the output impedance is limited to $665 \mathrm{~K} \Omega$ at $100 \mathrm{KHz}$ decreasing to $62 \mathrm{~K} \Omega$ at $1 \mathrm{MHz}$.

This paper presents the design and simulation of a current driver architecture providing high output impedance at $\alpha$ and $\beta$ frequency ranges. The output voltage swing is maximized making it suitable for integrated designs operating from a low supply voltage. Section II presents the current driver topology as well as the design methodology. Simulation results and comparison with existing architectures are presented in Section III. Finally Section IV concludes the paper. 


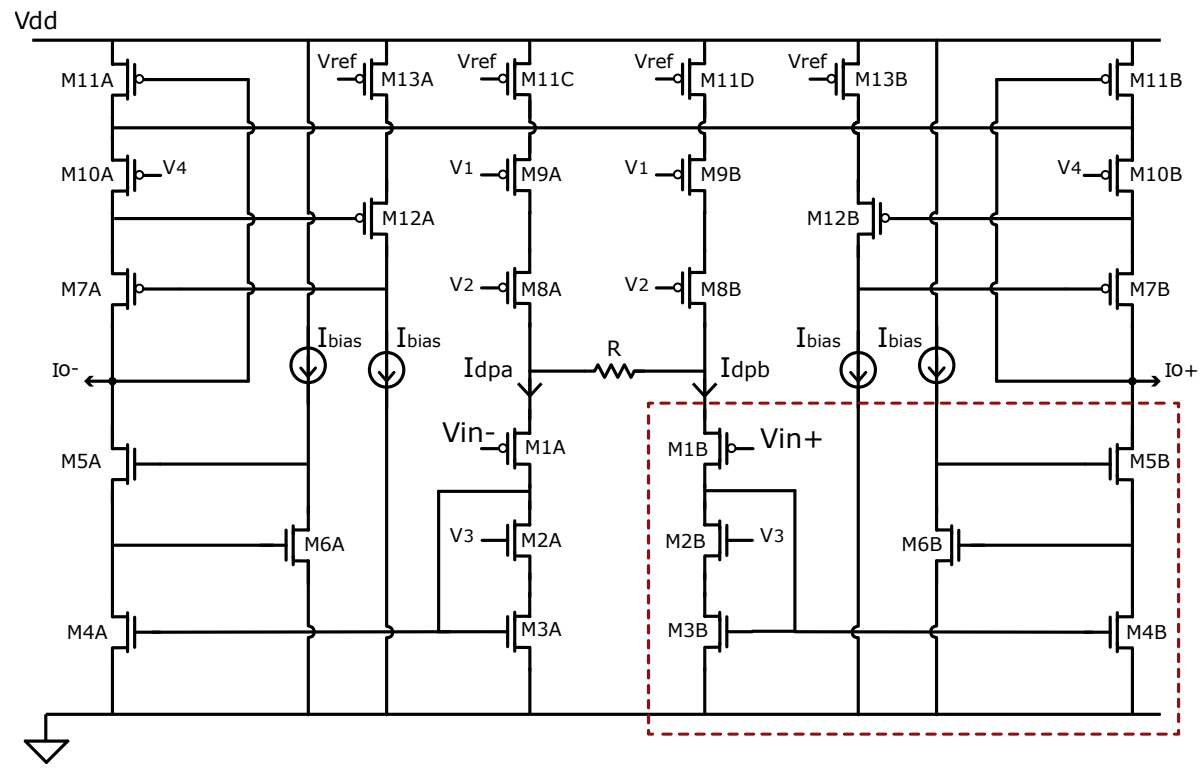

Fig. 1. Current driver architecture

\section{CURRENT DRIVER'S ARCHITECTURE OPTIMIZATION FOR BIOIMPEDANCE APPLICATIONS}

\section{A. Global architecture/Topology}

Fig.1 shows the architecture of the current driver. It is a symmetrical fully-differential OTA. The first stage of the OTA consists of a degenerated differential pair. A degeneration resistance was added to the M1 transistors in order to enhance the linearity of the transfer function and to maximize the range of input voltage. The current across the differential pair branches has been set in order to have a bandwidth of operation covering the $\alpha$ and $\beta$ frequency dispersions.

The output stage is a critical part of the current driver structure. It needs to provide a high output impedance while enabling a maximum output swing. Using regulated cascodes current mirror as the output stage architecture provides the best compromise between a high output resistance and the lowest output voltage.

Since the OTA is fully-differential, a common-mode feedback (CMFB) loop is implemented to stabilize the commonmode output voltage at half supply [7]. Due to low supply voltage specifications and in order to compensate for process variations, the output DC level is tunable using an independent reference voltage (Vref).

\section{B. Output impedance increasing}

The output stage of the current driver is critical. It has to provide an output current proportional to the input current at the high impedance output node. The output current amplitude needs to be constant regardless of loading. The important factors defining the performance of the output stage are thus output impedance, minimum output voltage and accuracy.

Bandwidth specifications imposed by the application (bioimpedance spectroscopy) require the use of short channel MOSFETs. A size reduction of the transistors leads to a decrease in the output resistance. Simple current mirror

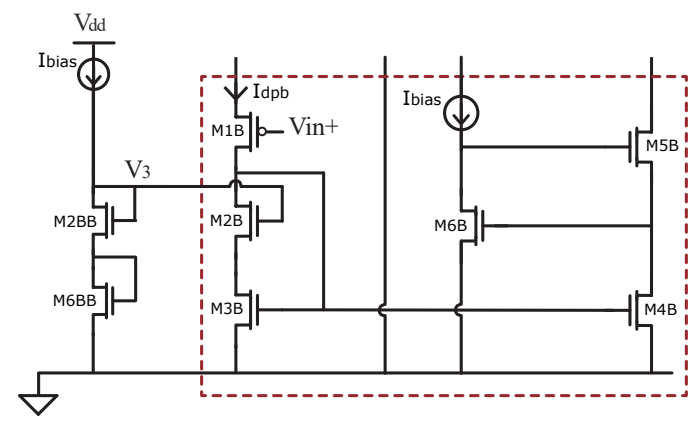

Fig. 2. Improved regulated cascode architecture

blocks or basic cascode structures are unable to provide an acceptable output resistance, especially at low frequencies where the load (electrode-tissue interface impedance) displays the highest impedance magnitudes, generating measurements errors in that frequency range. Therefore, improved output stage architectures for higher performances should be used.

Regulated cascode current mirror have the highest output impedance compared to simple or Wilson cascodes. It uses negative feedback in order to enhance the output impedance.

The improved regulated cascode shown in Fig. 2 is the basic block of the output stage. In order to minimize loading effects, the transistor $M_{6 B}$ is used to enhance the output impedance by a $g m *$ ro factor compared to basic cascode structures. The output impedance of the improved regulated cascode can be written as :

$$
\text { Rout }=r o_{M_{4}} * r o_{M_{6}} * g m_{M_{6}} * r o_{M_{5}} * g m_{M_{5}}
$$

The main drawback of the regulated cascode is the output minimum voltage, which is equal to $V_{t h}+2 V_{e f f}$. This could be improved to around $2 V_{\text {eff }}$ by using the $M_{6}$ transistors in weak inversion. Although the matching of the $M_{6}$ transistors 
will be affected when operating in weak inversion, the loop gain of the structure is so important that the matching errors are negligible.

In order to enhance the accuracy of the current mirror, the drain to source voltages of $M_{3 B}$ and $M_{4 B}$ should be equalized. Since the $V_{d s}$ of $M_{4 B}$ is imposed by the gate voltage of $M_{6 B}$, the proposed solution consists in using in a mesh an $M_{6 B B}$ transistor of similar size as $M_{6 B}$ biased with the same current, together with an $M_{2 B B}$ transistor of similar $V_{g s}$ as $M_{2 B}$ :

$$
\begin{gathered}
V_{d s_{M_{4 B}}}=V_{g s_{M_{6 B}}} \\
V_{g s_{M_{6 B}}}=V_{g s_{M 6 B B}} \\
V_{d s_{M_{3 B}}}=V_{g s_{M_{2 B} B}}-V_{g s_{M_{2 B}}}+V_{g s_{M_{6 B} B}} \\
V_{d s_{M_{3 B}}}=V_{g s_{M_{6 B} B}}=V_{d s_{M_{4 B}}}
\end{gathered}
$$

\section{Output voltage swing maximization}

Due to the low voltage supply specifications and the need for high output current amplitudes in order to ease the response analysis, the output voltage swing is a critical parameter of the current driver. Also, in implanted measurements applications, the electrode-tissue interface impedance may increase over time due to biological effects such as fibrosis. To avoid saturation errors, the output voltage swing should be maximized.

In order to maximize the output swing voltage, the architecture of the OTA should be carefully chosen. The symmetrical architecture offers the highest output swing voltage compared to the folded cascode or the telescopic toplogies [7]. OTA based current drivers could be single-ended or fullydifferential. Fully-differential current driver have twice the output voltage swing compared to the single-ended architectures, which has the advantage to allow for doubling the range of impedances that can be measured.

The common-mode feedback is implemented using $M_{11}$ transistors as follows: output voltages are measured by $M_{11 A}$ and $M_{11 B}$ transistors, then the drains of the $M_{11 A}$ and $M_{11 B}$ transistors are connected to cancel the differential signal and the loop is closed. The gate voltages of $M_{11 C}$ and $M_{11 D}$ are controlled by an independent reference voltage. If the gate voltages of $M_{11 C}$ and $M_{11 D}$ are set to the half supply voltage, by matching $M_{11 A}-M_{11 B}$ to $M_{11 C}-M_{11 D}$ the output voltages are set to half supply voltage.

Another solution consists in only using $M_{11 A} / M_{11 B}$ transistors in their triode region without using a reference voltage as in [6]. However this solution is subject to process variations. In low supply voltage driven designs, the output common mode voltage should be accurately set to half supply voltage. In order to compensate for process variations, the $M_{11 C} / M_{11 D}$ gates are driven by an adjustable reference voltage that consists in a multi-level digitally controlled voltage divider.

\section{RESULTS}

The current driver was designed in a $0.18 \mu \mathrm{m}$ AMS CMOS process operating at $1.8 \mathrm{~V}$ power supply. The current driver is capable of providing currents up to $600 \mu \mathrm{A}$ peak to peak. Fig.6 shows the layout of the circuit, the current driver occupies an area of $0.26 \mathrm{~mm}^{2}$. The circuit design, simulations and layout were developed with Cadence suite using the toolkit provided by the foundry.

The Frequency response of the current driver transconductance is presented in Fig.3. It has a transconductance of $860 \mu \mathrm{S}$ up to $4 \mathrm{MHz}$ decreasing to $854 \mu \mathrm{S}$ at $8 \mathrm{MHz}$. The cutting frequency is located at $67 \mathrm{MHz}$. The current driver was loaded with a $1 \mathrm{k} \Omega$ resistor with only its intrinsic stray capacitance.

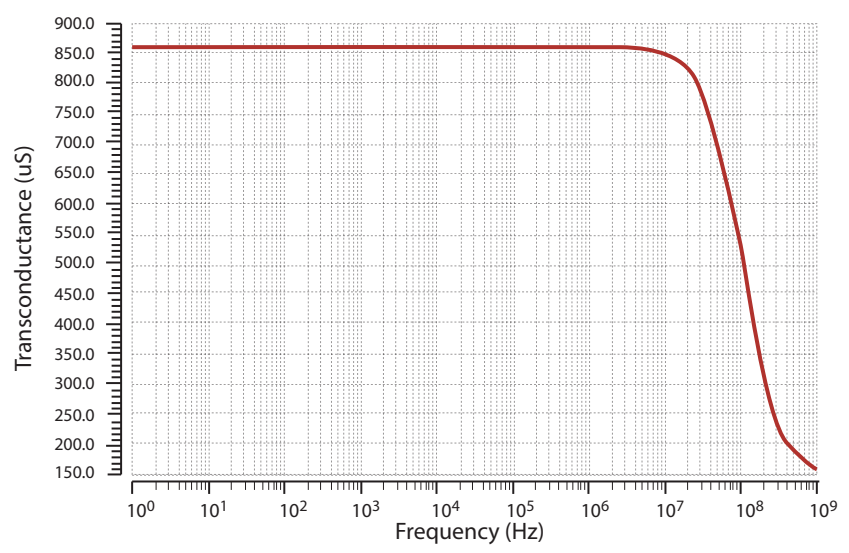

Fig. 3. Current driver bandwidth

Total Harmonic Distortion (THD) was simulated for a $400 \mu \mathrm{A}$ peak to peak output current. The simulation results have showed a THD below $0.3 \%$ at low frequencies increasing to $0.6 \%$ at $8 \mathrm{MHz}$.

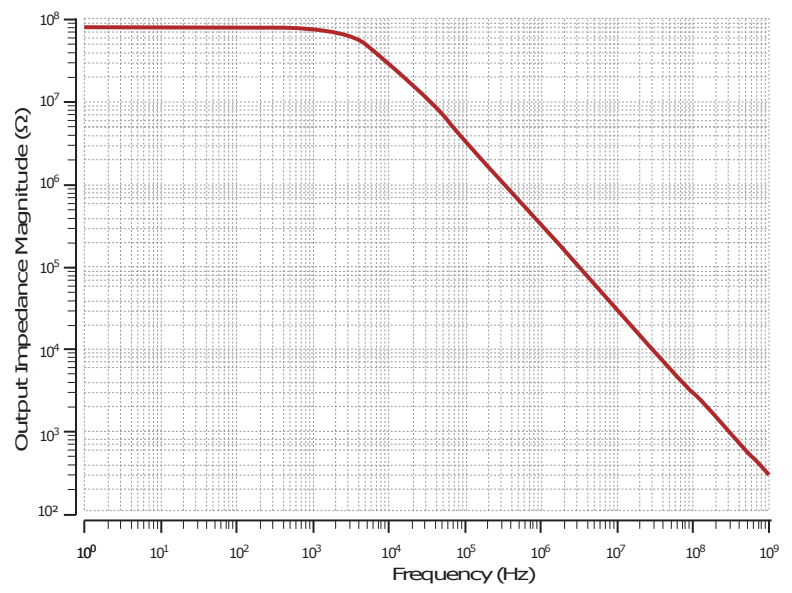

Fig. 4. Output impedance of the current driver

\section{A. Output impedance}

The frequency response of the output impedance of the current driver is presented in Fig.4. The output impedance is equal to $79 \mathrm{M} \Omega$ at $\mathrm{DC}$ up to $1 \mathrm{KHz}$. It decreases to $3.6 \mathrm{M} \Omega$ at $100 \mathrm{KHz}$, and to $324 \mathrm{k} \Omega$ at $1 \mathrm{MHz}$. The low frequency output impedance magnitudes are suitable for exploring the physiological processes occurring in the $\alpha$ region. At higher frequencies, the output impedance values are several orders of magnitude higher than the electrode-tissue impedance, since it is expected to decrease in the $\beta$ region. A research presented in [11] shows a comparison of the impedance magnitudes of several $\mathrm{Ag} / \mathrm{AgCl}$ commercial electrodes in the frequency 
TABLE I. RESULTS COMPARISON WITH EXISTING ARCHITECTURES

\begin{tabular}{|c|c|c|c|c|c|}
\hline Architectures & [8] & [9] & [10] & [6] & Our work \\
\hline Bandwidth & $1 \mathrm{KHz}-1 \mathrm{MHz}$ & $10 \mathrm{KHz}-250 \mathrm{KHz}$ & $100 \mathrm{~Hz}-100 \mathrm{KHz}$ & $>500 \mathrm{KHz}$ & $10 \mathrm{~Hz}-10 \mathrm{MHz}$ \\
\hline Output impedance & $\begin{array}{l}670 \mathrm{k} \Omega @ 100 \mathrm{kHz} \\
330 \mathrm{k} \Omega @ 300 \mathrm{KHz}\end{array}$ & $\begin{array}{l}149 \mathrm{k} \Omega @ 100 \mathrm{KHz} \\
30 \mathrm{k} \Omega @ 500 \mathrm{KHz}\end{array}$ & $100 \mathrm{k} \Omega @ 100 \mathrm{KHz}$ & $\begin{array}{c}665 \mathrm{k} \Omega @ 100 \mathrm{kHz} 372 \mathrm{k} \Omega @ 500 \mathrm{kHz} \\
64 \mathrm{k} \Omega @ 1 \mathrm{MHz}\end{array}$ & $\begin{array}{c}79 \mathrm{M} \Omega @ 100 \mathrm{~Hz} 3.24 \mathrm{M} \Omega @ 100 \mathrm{KHz} \\
324 \mathrm{k} \Omega @ 1 \mathrm{MHz}\end{array}$ \\
\hline THD & - & $0.45 \% @ 1 \mathrm{~mA}_{p p}$ & $0.2 \% @ 200 \mu \mathrm{A}_{p p}$ & $0.53 \% @ 2 \mathrm{~mA}_{p p}$ & $0.3 \% @ 400 \mu \mathrm{A}_{p p}$ \\
\hline Output swing & - & - & $0.4 \mathrm{~V}$ & $15 \mathrm{~V}$ & $0.95 \mathrm{~V}$ \\
\hline Supply voltage & - & $30 \mathrm{~V}$ & $1.8 \mathrm{~V}$ & $18 \mathrm{~V}$ & $1.8 \mathrm{~V}$ \\
\hline
\end{tabular}

range $(10 \mathrm{~Hz}-1 \mathrm{MHz})$, The average electrode-tissue impedance magnitudes were higher than $10 \mathrm{~K} \Omega$ for frequencies below $10 \mathrm{KHz}$, equal to $5 \mathrm{~K} \Omega$ at $10 \mathrm{KHz}$ and $337 \Omega$ at $1 \mathrm{MHz}$. The current driver output impedance results compared to the electrode-tissue magnitudes presented in [11] show that it is capable of providing measurements with an error of $0.02 \%$ at $10 \mathrm{KHz}$ and $0.1 \%$ at $1 \mathrm{MHz}$.

\section{B. Output voltage swing}

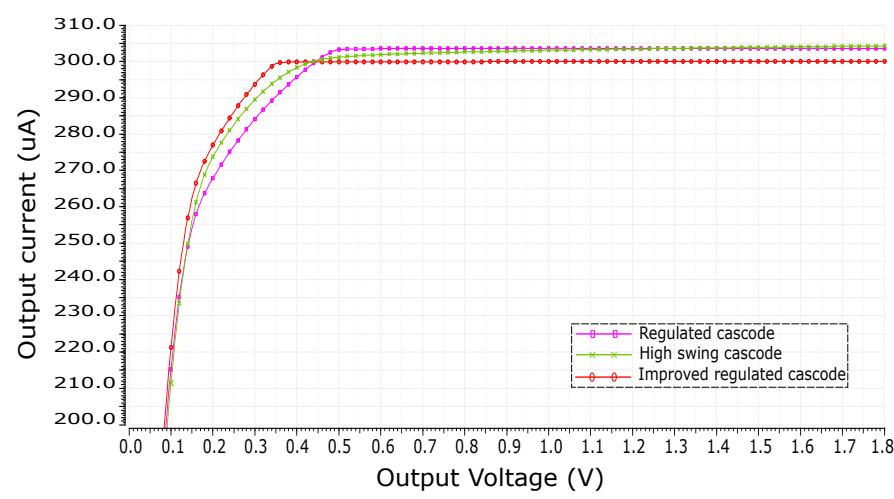

Fig. 5. Output current vs output voltage characteristic of the high swing cascode, the regulated cascode and the improved regulated cascode for an input current of $300 \mu \mathrm{A}$

Fig.5 shows the output current versus the output voltage characteristic of the NMOS improved regulated cascode presented in section II compared with the characteristics of the high swing cascode and the classic regulated cascode. For the high swing cascode, output resistance is minimal. While the classic regulated cascode provides high output resistance, the output current is not accurate, and the output minimum voltage is maximal (around $0.55 \mathrm{~V}$ ). The improved regulated cascode presented in section II provides high output impedance, high accuracy and low minimum output voltage $(0.4 \mathrm{~V})$.

The common mode transistors $\left(M_{11}\right)$ were designed for a $V_{\text {eff }}$ of $50 \mathrm{mV}$. This value is a compromise between the overall output swing and the variability of the common mode feedback transistors. A Montecarlo simulation (process and mismatch) of the DC output level showed a mean value of $901 \mathrm{mV}$ with a standard deviation of $9.91 \mathrm{mV}$.

Therefore, the overall output voltage swing is around $0.95 \mathrm{~V}$ from a supply voltage of $1.8 \mathrm{~V}$.

\section{Comparison table with existing architectures}

Table I presents a performance comparison with existing discrete design current driver architectures [8] [9] as well as

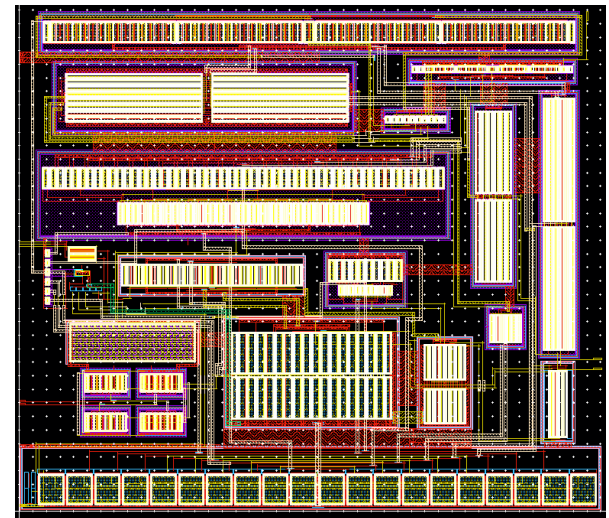

Fig. 6. Layout of the current source

integrated current driver architectures [10][6] for bioimpedance measurement application. However, only simulation results are available for the proposed architecture whereas the cited architectures present measurement results. For a fair comparison with the integrated current driver architectures, the output impedance magnitudes are simulated for a $400 \mu \mathrm{A}$ peak to peak output current as in [6] and [10]. Regarding the constrains induced by the need for bioimpedance measurement over a wide frequency range, the comparison table shows that our proposed architecture provides the highest output impedance magnitudes over the widest frequency range.

\section{COnClusion}

A current driver architecture optimized for bioimpedance measurements has been presented. It uses an improved regulated cascode to enhance the output impedance, enabling accurate measurements of transfer impedances at low and high frequencies. The current driver uses a common-mode feedback compensation technique capable of accurately setting the output common mode voltage independently of process variations. The proposed architecture offers a high output swing for a given supply voltage. A circuit implementing the design methodology was designed and simulated in a $0.18 \mu \mathrm{m}$ CMOS AMS process. It occupies an area of $0.26 \mathrm{~mm}^{2}$.

\section{ACKNOWLEDGMENT}

This research was part of the MERLIN-POPSTAR project funded by Ifremer and a Phd funded by Ifremer and labex Numev. We thank our colleagues from Ifremer/REM/RDT and RBE, CNRS, UM and IRD who provided insight and expertise that greatly assisted the research. 


\section{REFERENCES}

[1] S. Grimnes and O. G. Martinsen, Bioimpedance and Bioelectricity Basics. Academic Press, 2014.

[2] H. P. Schwan, "Electrical properties of tissue and cell suspensions," Advances in Biological and Medical Physics, vol. 5, pp. 147-209, 1957.

[3] H. Dastjerdi, R. Soltanzadeh, and H. Rabbani, "Designing and implementing bioimpedance spectroscopy device by measuring impedance in a mouse tissue." Journal of Medical Signals and Sensors, pp. 187-194, 2013.

[4] A. S. Tucker, R. M. Fox, S. Member, and R. J. Sadleir, "Biocompatible, High Precision, Wideband, Improved Howland Current Source With Lead-Lag Compensation,” pp. 1-8, 2012.

[5] H. Hong, A. Demosthenous, I. F. Triantis, P. Langlois, and R. Bayford, "A high output impedance CMOS current driver for bioimpedance measurements," 2010 IEEE Biomedical Circuits and Systems Conference, BioCAS 2010, pp. 230-233, 2010.

[6] L. Constantinou, R. Bayford, and A. Demosthenous, "A Wideband Low Distortion CMOS Current Driver for Tissue Impedance Analysis," IEEE Transactions on Circuits and Systems II: Express Briefs, no. c, pp. 1-1, 2015.

[7] W. M. C. Sansen, Analog Design Essentials. Springer, 2006.

[8] P. Bertemes-Filho, B. H. Brown, and a. J. Wilson, "A comparison of modified Howland circuits as current generators with current mirror type circuits." Physiological measurement, vol. 21, no. 1, pp. 1-6, 2000.

[9] O. Casas, J. Rosell, R. Bragós, a. Lozano, and P. J. Riu, "A parallel broadband real-time system for electrical impedance tomography." Physiological measurement, vol. 17 Suppl 4, pp. A1-A6, 1996.

[10] S. Hong, K. Lee, and U. Ha, "A 4 . 9 m -Sensitivity Mobile Electrical Impedance Tomography IC for Early Breast-Cancer Detection System," IEEE Journal of Solid-State Circuits, vol. 50, no. 1, pp. 245-257, 2015.

[11] M. Rahal, J. M. Khor, A. Demosthenous, A. Tizzard, and R. Bayford, "A comparison study of electrodes for neonate electrical impedance tomography," Physiological Measurement, vol. 30, no. 6, p. S73, 2009. [Online]. Available: http://stacks.iop.org/0967-3334/30/i=6/a=S05 